\title{
Large Inclusions in Plain-carbon Steel Ingots Cast by Bottom Teeming
}

\author{
Lifeng ZHANG ${ }^{1)}$, Bret RIETOW, ${ }^{2)}$ Brian G. THOMAS ${ }^{3)}$ and Ken EAKIN ${ }^{4)}$ \\ 1) Department of Materials Science and Engineering, Norwegian University of Science and Technology (NTNU), \\ Høgskoleringen 8, 7491 Trondheim, Norway. E-mail: lifeng.zhang@material.ntnu.no \\ 2) Formerly Master Student at Department of Mechanical \& Industrial Engineering, University of Illinois at Urbana- \\ Champaign, 1206 W. Green St., Urbana, IL 61801, USA. $\quad 3)$ Department of Mechanical \& Industrial Engineering, \\ University of Illinois at Urbana-Champaign, 1206 W. Green St., Urbana, IL 61801, USA. E-mail: bgthomas@uiuc.edu \\ 4) Ellwood Quality Steel Company, 700 Moravia St., New Castle, PA 16101 USA. E-mail: KEAKIN@elwd.com
}

(Received on October 27, 2005; accepted on March 7, 2006)

\begin{abstract}
Inclusions in industrial-cast bottom-teemed ingots of plain carbon steel are investigated using ultrasonic detection, optical microscope observation, and SEM analysis. The composition, size distribution, entrapment locations, and sources of ingot inclusions were revealed by examining all the macro-inclusions (larger than $20 \mu \mathrm{m}$ ) that were observed in $35000 \mathrm{~mm}^{2}$ of sample surface area. Based on 78 non-sulfide inclusions observed, around $3.23 \times 10^{7}$ macro-inclusions per $\mathrm{m}^{3}$ steel exist in the ingot, with a size distribution increasing with decreasing size. Inclusions are distributed uniformly within a given horizontal section through the ingot, but with more found towards the bottom. The largest inclusions exceed $7 \mathrm{~mm}$ and originate from mold flux in the ingot. The largest inclusion source appears to be reoxidation, as evidenced by $59 \%$ of the ingot inclusions composed of pure alumina clusters and lumps. Eroded refractories from the ladle well block and ladle inner nozzle bricks accounted for $31 \%$ of the ingot inclusions.
\end{abstract}

KEY WORDS: steel ingot; inclusions; mold flux; alumina; exogenous inclusions.

\section{Introduction and Methodology}

Although the fraction of steel produced in the world via ingot casting has decreased to $11.2 \%$ in 2003 , this still comprised 108.7 million metric tonnes, including about 2.5 million tonnes in US. ${ }^{1)}$ Ingot casting is still important because some low-alloy steel grades and steel for special applications can only be produced by this process. These include high carbon chromium bearing steel, ${ }^{2)}$ thick plate, seamless tube, forgings, bars and wire rods. ${ }^{3)}$

The ever-increasing demands for high quality have made the steelmaker increasingly aware of the necessity for products to meet stringent "cleanliness" requirements. Nonmetallic inclusions are a significant problem in cast steels that can lead to problems in castings that require expensive casting repairs or rejection. The mechanical properties of steel are controlled to a large degree by the volume fraction, size, distribution, composition and morphology of inclusions and precipitates, which act as stress raisers. For example, ductility is appreciably decreased with increasing amounts of either oxides or sulphides. ${ }^{4)}$ Fracture toughness decreases when inclusions are present, especially in higherstrength lower-ductility alloys. Similar pronounced property degradation caused by inclusions is observed in tests that reflect slow, rapid, or cyclic strain rates, such as creep, impact, and fatigue testing. ${ }^{4)}$ Pomey and Trentini studied the inclusion removal in ingots from with various deoxidants. ${ }^{5)}$ Franklin, ${ }^{6}$ and Miki et al. ${ }^{7)}$ obtained a rough inclusion size distribution in steel ingots. Hilty and Kay, ${ }^{8)}$ Pickering, ${ }^{9)}$ and Lunner ${ }^{10)}$ investigated the compound exogenous inclusions in steel ingots by microscope and SEM analysis. Thomas et al. ${ }^{11)}$ and Leach ${ }^{12)}$ investigated the sources of exogenous nonmetallic inclusions in steel ingots. Inclusions, especially large exogenous inclusions are perhaps the most serious problem affecting steel ingots, and arise primarily from the incidental chemical and mechanical interaction of the liquid steel with its surroundings. Refractory erosion of the ladle and metal delivery system introduce inclusions that can impair the quality of what was otherwise very clean refined steel. ${ }^{3,9,13-18)}$ In addition, air entrainment ${ }^{8,19}$ ) during teeming generates reoxidation inclusions, such as alumina clusters in Al-killed steels, and the turbulent flow and mixing with the teeming flux during the initial entry of steel into the mold can induce flux entrainment ${ }^{20-26,27)}$ during solidification. Inclusion distribution in an ingot is affected by fluid flow, heat transfer and solidification of the steel. Two studies ${ }^{10,28)}$ of top-poured ingots found larger slag inclusions concentrate in the central bottom portion of the ingot, and in the outer portions of the ingot top. It was reported that increased teeming temperature decreases the amount of inclusions, because it facilitates their floatation removal by natural convection. For a bottom-poured $2 \mathrm{t}$ ingot (with taper) of $0.50 \% \mathrm{C}, \mathrm{Al}-\mathrm{Si}-\mathrm{Killed}$ steel, the highmelting-point inclusions (high alumina) predominate at the bottom of the ingot, while low-melting-point inclusions (sulphide and silicates) are more abundant in its top central 
Table 1. Steel composition in the trial.

\begin{tabular}{|l|l|l|l|l|l|l|l|l|l|l|}
\hline Elements & {$[\mathrm{C}]$} & {$[\mathrm{P}]$} & {$[\mathrm{S}]$} & {$[\mathrm{Al}]$} & {$[\mathrm{Si}]$} & {$[\mathrm{Mn}]$} & {$[\mathrm{Ni}]$} & {$[\mathrm{Cr}]$} & {$[\mathrm{Mo}]$} & {$[\mathrm{Cu}]$} \\
\hline$\%$ & .22 & .011 & .014 & .029 & .26 & 1.01 & .09 & .11 & .02 & .17 \\
\hline
\end{tabular}

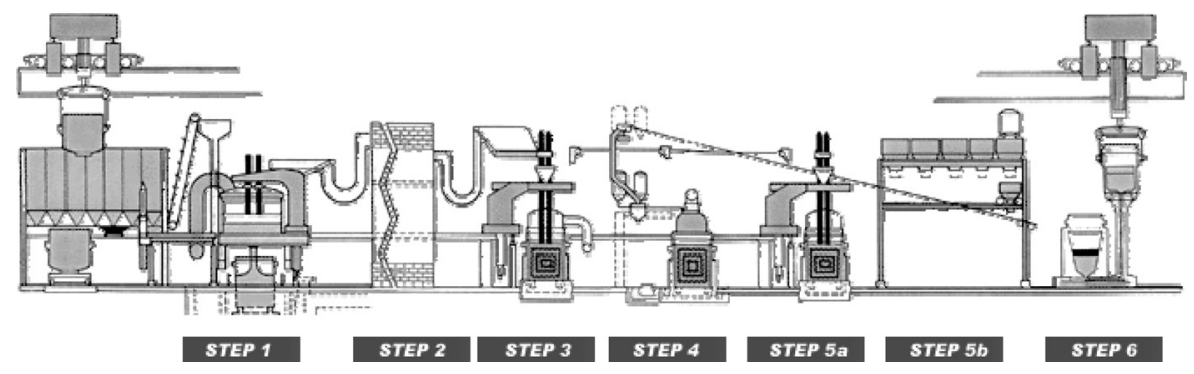

Fig. 1. Schematic of ingot production process.

portion, due to the mechanism of positive segregation. ${ }^{29)}$ It should be noticed that most of these papers on inclusions in steel ingots were published before 1990s, and very few are published in recent 15 years.

This current work is part of a larger project to investigate inclusions in bottom-teemed steel ingots by combining computational models and plant experiments conducted at member companies of the Ingot Metallurgy Forum. A survey with responses from six steel ingot producers in the US revealed that the total annual tonnage of bottom-poured ingots where cleanliness is a concern is at least 700000 tons. Rejections at these companies due to inclusion defects range from $0.2-5 \%$ with a cost of \$900-3600/tonne (depending on grade). This corresponds to $\$ 10$ million per year (assuming a typical rejection rate of $1 \%$ at $\$ 1500$ / ton). From the survey replies, $10-25 \%$ of defects sources are estimated to be related to ladle sand/packing sand entrapment, 25-50 from mold flux entrainment, 0-5\% from runner erosion, and $0-35 \%$ related to other exogenous inclusion sources. In addition to the above exogenous inclusion sources, the companies estimated that $0-15 \%$ of their defects were from alumina inclusions (deoxidation products), $0-20 \%$ from air absorption, $0-5 \%$ from reoxidation reactions with slag and refractory, and $0-10 \%$ from unknown sources. Clearly, exogenous defects are the greatest problem. The actual amount and nature of these inclusion sources is investigated in the present work, based on industrial trials conducted at Ellwood Quality Steels Co.

\section{Process Description and Methodology}

This work investigates large inclusions measured in a bottom-teemed ingot of 1022 carbon steel, with a composition (ladle analysis) shown in Table $\mathbf{1 .}$

The ingot production process of concern is shown Fig. 1 and is described as follows:

Step 1: Scrap is loaded into clam-shell buckets and charged into an ultra high powered (UHP) eccentric bottom tapping (EBT) electric arc furnace. The scrap is melted and refined to remove carbon and phosphorus using an oxidizing slag.

Step 2: The EBT feature minimizes heat loss and allows the liquid steel to be tapped relatively slag-free into the ladle for further refining. During tapping, alloy additions are charged, including aluminum for deoxidation, followed by the addition of a reducing top slag.

Step 3: The ladle is transferred to a treatment station for heating, alloy adjustment and further refining. Arc heating and induction stirring at this step ensures mixing and interaction between the steel and the slag.

Step 4: The steel bath undergoes vacuum degassing where the hydrogen level is lowered to less than $1 \mathrm{ppm}$. Induction and argon gas stirring are combined during this step to optimize stirring energy.

Step 5: The ladle is transferred to a second treatment station, where the steel may be reheated, calcium treated via wire feeding. Final alloy adjustments are made as needed.

Step 6: Heats are bottom teemed into ingots at a designated temperature and a controlled rate of rise. Argon shrouding may be employed prior to teeming to minimize reoxidation and the pick-up of hydrogen and nitrogen. Argon shrouding was not used on the test ingots of this study, however.

For ladle opening, a slide gate is used. The free-open percentage is only about $50 \%$. This low percentage is a concern because it is well known from studies of continuous casting that lance-opening of ladles induces serious reoxidation, increasing total oxygen (T.O.) oxygen in the tundish to 10 ppm higher than that by free opening. ${ }^{30)}$ The ladle slag was mainly $\mathrm{CaO}$. Visual observation is the only method used to detect and prevent slag carryover into the trumpet during teeming, so the standard practice also requires extra metal in the ladle, so no slag pours into the trumpet. The teeming process delivers the steel down a trumpet, through a "spider" distributing the flow into 7-8 round-section runners with inner diameter of $50.8 \mathrm{~mm}$, across and up through inlets with the same diameter into each mold in a cluster of $7-8$ ingots. The compositions of the mold flux and refractories are shown in Table $\mathbf{2}$ and Fig. 2, including the ladle lining, well block, filler sand, trumpet, and runner bricks. Some of the refractory contains high $\mathrm{SiO}_{2}$, which is known to cause severe reoxidization of molten steel. ${ }^{31}$ )

The ingots in this study were round with $0.33 \mathrm{~m}$ diameter, $4.70 \mathrm{~m}$ height and 2.91 metric tonnes in weight. The total filling rate was around 1.4 tonne $/ \mathrm{min}(23 \mathrm{~kg} / \mathrm{s})$, with $3.3 \mathrm{~kg} / \mathrm{s}$ to each ingot. This increased the ingot level at $4.87 \mathrm{~mm} / \mathrm{s}$. The typical filling time was $13-18 \mathrm{~min}$, Mold 
Table 2. Composition of flux and linings used at ladle, trumpet, runner and ingot mold.

\begin{tabular}{|c|c|c|c|c|c|c|c|c|c|c|}
\hline & \multicolumn{6}{|c|}{ Ladle Lining } & \multirow{2}{*}{$\begin{array}{l}\text { Nozzle } \\
\text { Sand }\end{array}$} & \multicolumn{2}{|c|}{ Trumpet \& Runner } & \multirow[t]{2}{*}{ Mold Flux } \\
\hline & Wall & Bottom & $\begin{array}{l}\text { Well } \\
\text { block }\end{array}$ & $\begin{array}{l}\text { Inner } \\
\text { Nozzle }\end{array}$ & $\begin{array}{l}\text { Slide } \\
\text { gates }\end{array}$ & $\begin{array}{l}\text { Collector } \\
\text { Nozzle }\end{array}$ & & Brick & Filler & \\
\hline $\mathrm{SiO}_{2}$ & $0-5$ & 0.8 & 0.10 & 1.00 & 0.5 & $10-13$ & 27.6 & 50.8 & 0.9 & $29.0-36.0$ \\
\hline $\mathrm{Al}_{2} \mathrm{O}_{3}$ & $0-5$ & 0.5 & 91.22 & 94.00 & & $83-87$ & 11.8 & 44.5 & 0.8 & $15.0-21.0$ \\
\hline $\mathrm{MgO}$ & $80-100$ & 40.1 & 6.01 & Trace & 97.0 & & 7.1 & 0.1 & 37.7 & $<2.0$ \\
\hline $\mathrm{CaO}$ & & 57.6 & 2.51 & Trace & 1.8 & & 0 & 0.1 & 55.6 & $1.0-5.0$ \\
\hline $\mathrm{Fe}_{2} \mathrm{O}_{3}$ & 0.5 & 0.9 & 0.03 & & 0.2 & $1-2$ & 18.6 & 1.0 & 4.2 & $5.0-11.0$ \\
\hline $\mathrm{Na}_{2} \mathrm{O}$ & & & $<0.02$ & 0.20 & & $<1$ & & 0.47 & & $4.0-6.0$ \\
\hline $\mathrm{K}_{2} \mathrm{O}$ & & & & & & & & & & $<2.0$ \\
\hline $\mathrm{TiO}_{2}$ & & & 0.02 & & & $1-3$ & & 2.1 & & $<1.5$ \\
\hline $\mathrm{ZrO}_{2}$ & & & & 2.50 & & & 0 & & & \\
\hline $\mathrm{Cr}_{2} \mathrm{O}_{3}$ & & & & & & & 32.9 & & & \\
\hline $\mathrm{MnO}$ & & & & & & & & & & $<1.0$ \\
\hline $\mathrm{F}$ & & & & & & & & & & $<0.5$ \\
\hline $\mathrm{C}_{\text {total }}$ & $5-15$ & & & & & & 0.6 & & & $23.0-26.0$ \\
\hline
\end{tabular}
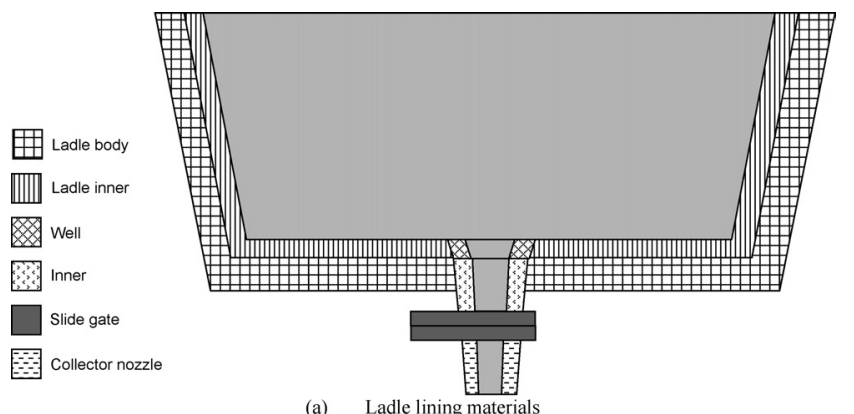

(a) Ladle lining materials

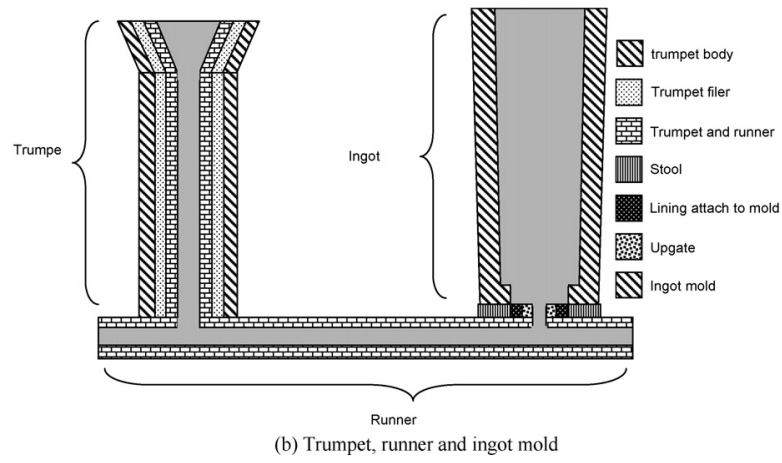

Fig. 2. Schematic of bottom teeming process.

powder was added by placing a $5-\mathrm{kg}$ bag on the bottom of each ingot prior to teeming. Some operations suspend the bags of powder above the bottom to lessen powder entrapment during the start of filling. ${ }^{25)}$ Important topics of interest include the filling rate (rate of rise), the delivery-system geometry, which may cause turbulence and encourage mold powder entrapment, slag entrapment by vortexing near the ladle nozzle at the end of teeming, argon shrouding, and the erosion of refractories.

After final solidification, the ingot was sectioned. Figure 3 diagrams how the samples were obtained, where "A" indicates the direction away from runner from the trumpet. In total, 54 cube-shaped steel samples of $25.4 \mathrm{~mm}$ ( 1 inch) per side were examined for inclusions. The total observation area was almost $35000 \mathrm{~mm}^{2}$. In addition, the solidified runner bar/spider for this ingot was also examined. After polishing, the samples were first observed under an optical microscope to mark the locations of all inclusions larger than $20 \mu \mathrm{m}$ in diameter. Then, the detailed morphology and composition of each inclusion was analyzed by scanning electron microscope (SEM) using Energy Dispersive X-Ray Analysis. Almost all of the large non-sulfide inclusions were photographed. In addition, several sample pho-

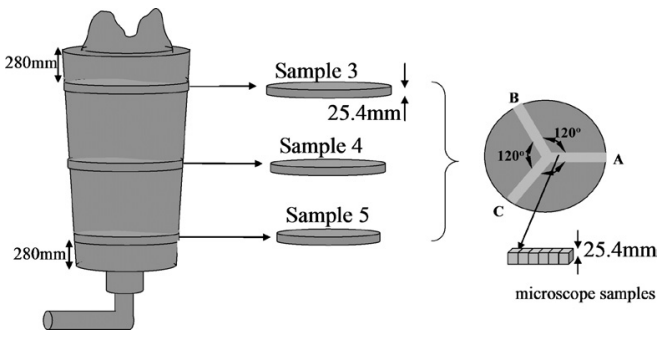

Fig. 3. Schematic of sampling locations in 13 inch round ingot (A is away from the trumpet).

tographs were taken of the much more common indigenous sulfide inclusions, and of the numerous holes (voids) that were larger than $20 \mu \mathrm{m}$.

The results of these detailed tests were compared with standard industrial tests of ingot cleanliness. Another ingot from the same cluster was cut into two 84-inch lengths with the hot top and ingate left intact. These pieces were forged into $\phi 7.5$ inch bars, measuring 238 inch in length. After machining away $6 \mathrm{~mm}(0.25 \mathrm{in}$.) of the surface layer, inclusions in the resulting $\phi 7$ inch bars, were detected using standard Ultra Sonic Scanning (USS).

\section{Ingot Inclusions Analysis}

\subsection{Ultra Sonic Detection}

In the forged bar samples detected by Submerged Ultra Sonic Scanning. ${ }^{32}$ ) This method is used for detecting large inclusions or defects in the steel sample (as large as in tones), which is submerged in water in a tank during detection. Using this method in the current study, only two inclusions were detected. As shown in Fig. 4, one of these macro-size nonmetallic inclusions was uncovered at the top end of the bottom bar while trimming the end. This huge defect exceeded $20 \mathrm{~mm}$ in length, even after forging. It contained $\mathrm{O}, \mathrm{Na}, \mathrm{Mg}, \mathrm{Al}, \mathrm{Si}, \mathrm{K}, \mathrm{Mn}, \mathrm{S}$, and $\mathrm{Ca}$, indicating it to originate from mold flux. The fact that so few exogenous inclusions were found by Ultra Sonic Detection indicates that this method can reveal only large inclusions, exceeding $\sim 1 \mathrm{~mm}$ in diameter. It is crucial to detect such large and rare inclusions. However, determining the true cleanliness of the steel also requires microscope observation and SEM detection.

\subsection{Microscope Observation and SEM Detection}

Typical inclusions detected by optical microscope obser- 


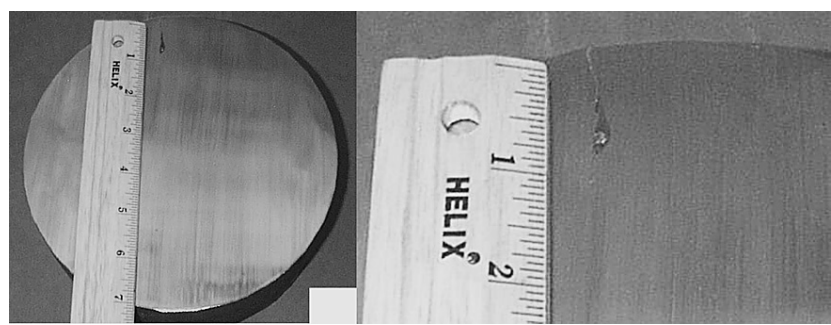

Fig. 4. Large nonmetallic inclusions found in the forged ingot.

Table 3. Comparison of 2D microscope and 3D SEM images of typical inclusion-related defects.

\begin{tabular}{|c|c|c|c|}
\hline & $\begin{array}{l}\text { Two dimensional } \\
\text { microscope observation }\end{array}$ & $\begin{array}{l}\text { Three-dimensional SEM } \\
\text { detection }\end{array}$ & \\
\hline S1 & & $40 \mu \mathrm{m}$ & $\begin{array}{l}\text { Partially- } \\
\text { dislodged } \\
\text { pure } \\
\text { alumina } \\
\text { cluster }\end{array}$ \\
\hline S2 & & & $\begin{array}{l}\text { Pure } \\
\text { alumina } \\
\text { cluster }\end{array}$ \\
\hline S3 & & $30 \mu \mathrm{m}$ & $\begin{array}{l}\text { Pure } \\
\text { alumina } \\
\text { lumps }\end{array}$ \\
\hline S4 & 18 & सी & $\begin{array}{l}\text { Irregular- } \\
\text { shaped hole } \\
\text { remaining } \\
\text { after } \\
\text { inclusion } \\
\text { was } \\
\text { polished } \\
\text { away }\end{array}$ \\
\hline S5 & & $100, m$ & $\begin{array}{l}\text { Hole } \\
\text { between } \\
\text { dendrite } \\
\text { arms caused } \\
\text { by micro- } \\
\text { porosity }\end{array}$ \\
\hline S6 & 6 & $\frac{70 \mu \mathrm{m}}{2}$ & $\begin{array}{l}\text { Bubble- } \\
\text { shaped } \\
\text { cavity with } \\
\text { sulfide } \\
\text { inclusions in } \\
\text { its wake. }\end{array}$ \\
\hline
\end{tabular}

vations and the corresponding SEM image of the same inclusions/holes are compared in Table 3. The SEM reveals the true morphology of the defects more clearly than the microscope observations. Defects S1 and S5 appear to look like inclusions under microscope observation. However, the SEM images clearly reveal that S1 is an inclusion cluster with a hole, and S5 is interdendritic porosity. The SEM images also show that $\mathrm{S} 2$ is an inclusion cluster rather than a square-shaped inclusion as it appears under the microscope; S4 is a an irregular-shaped hole remaining after the inclusions were polished away, rather than a simple inclusion; and S6 is a bubble-shaped circle rather than an inclusion. These results indicate the short-comings of inclusion detection by ultra-sonic detection or optical microscopy alone, and the power of the combining these two methods with de-
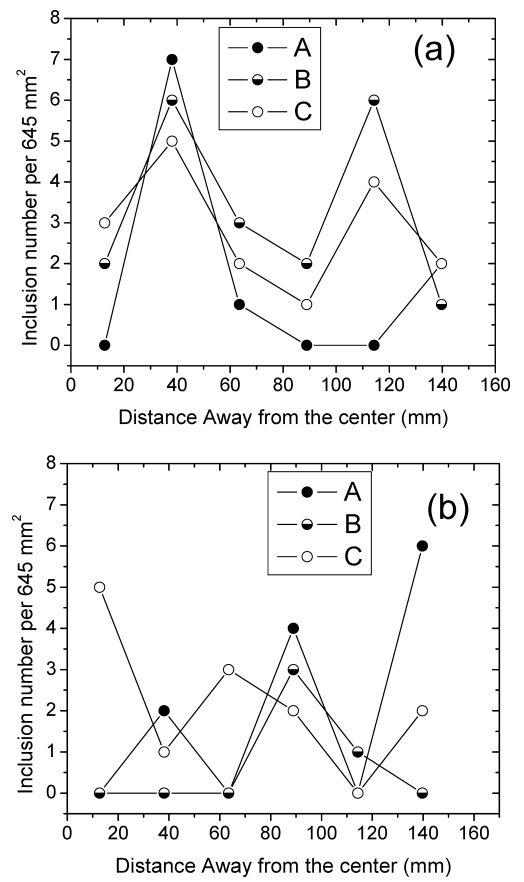

Fig. 5. Inclusions $(>20 \mu \mathrm{m})$ observed at $280 \mathrm{~mm}$ from bottom (left) and half height (2350 $\mathrm{mm}$ from the bottom) (right) of the ingot.

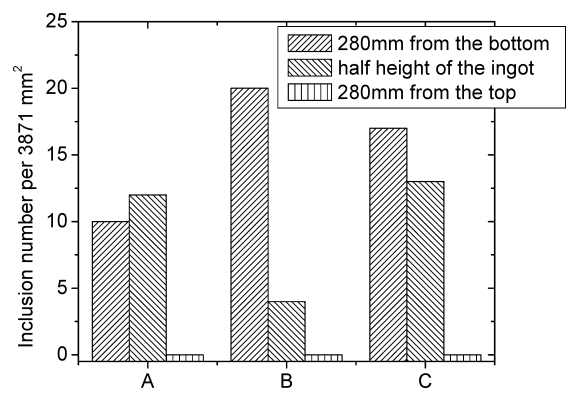

Fig. 6. Inclusions $(>20 \mu \mathrm{m})$ in ingot samples (A: direct away from trumpet, B \& C: close to the trumpet).

tailed SEM analysis of previously-detected inclusions.

\subsection{Inclusion Amount and Size Distribution}

The total of 78 non-sulfide inclusions larger than $20 \mu \mathrm{m}$ that were detected in the ingot are plotted in Figs. 5 and 6 according to their location along each bar-sample. In the $11613 \mathrm{~mm}^{2}$ total area observed at each of three ingot heights, most (47) of these large inclusions were observed on the section near the ingot bottom (sample 5), 29 on the half-height samples, and no inclusions were found on the ingot upper section. Thus, the most important trend in entrapment location is a decrease in inclusions with height up the ingot. At the ingot bottom, inclusions appear to concentrate in two regions, peaking at $40 \mathrm{~mm}$ from the center line and at $20 \mathrm{~mm}$ from the surface. At the ingot half height, inclusions are distributed more randomly, although there may be a slight concentration at the ingot surface. At every height, inclusions are randomly distributed around the ingot perimeter, but there may be a slight trend of more inclusions towards the trumpet side of the ingot near the ingot bottom.

The inclusion size distribution from the two-dimensional 
microscope observations is shown in Fig. 7, and was converted into the three-dimensional size distribution in Fig. 8, using Eq. (1).

$$
n_{3 \mathrm{D}}=\frac{n_{2 \mathrm{D}}}{d_{\mathrm{p}}} \times 10^{12}
$$

where $n_{2 \mathrm{D}}$ is the number of inclusions per $\mathrm{mm}^{2}$ of steel surface area, $d_{p}$ is inclusion diameter in $\mu \mathrm{m}$ under 2Dimensional (2D) microscope observation, $n_{3 \mathrm{D}}$ is the number of inclusions per $\mathrm{m}^{3}$ of steel volume. Here it is assumed that the diameter of inclusions under 2D microscope observation is the same as that of the real $3 \mathrm{D}$ inclusions. Actually, the observed 2D diameter of the spherical inclusion is usually smaller than its $3 \mathrm{D}$ real diameter because the observed section surface is rarely just across the sphere's diameter, which means that the observed steel cleanliness underpredicts the inclusion fraction in the steel. This equation assumes that each inclusion is roughly, with height (into the plane) equal to its observed diameter. There are $\sim 3.23 \times 10^{7}$ total inclusions larger than $20 \mu \mathrm{m}$ per $\mathrm{m}^{3}$ of steel, including $9.57 \times 10^{5}$ inclusions larger than $200 \mu \mathrm{m}$ per $\mathrm{m}^{3}$ steel. The total mass of inclusions larger than $20 \mu \mathrm{m}$ is $62.7 \mathrm{mg} / 10 \mathrm{~kg}$ steel, assuming inclusion and steel densities

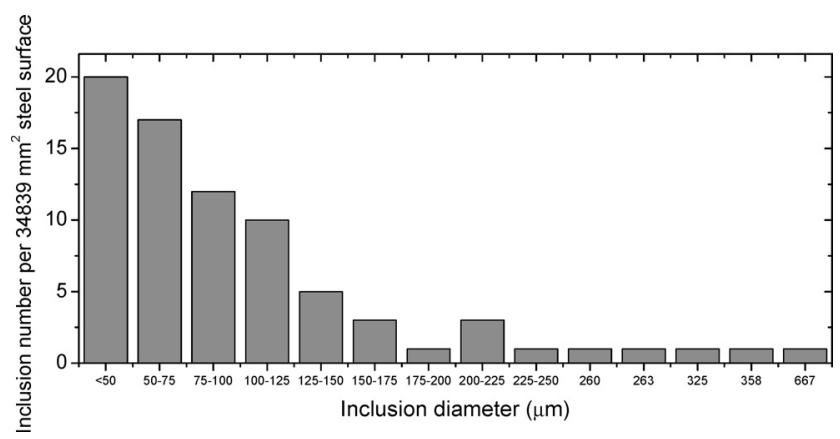

Fig. 7. Two-dimensional size distribution of inclusions by microscope observation.

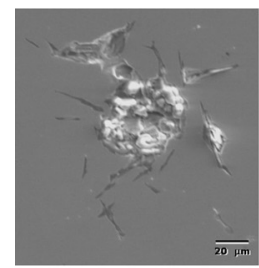

S7

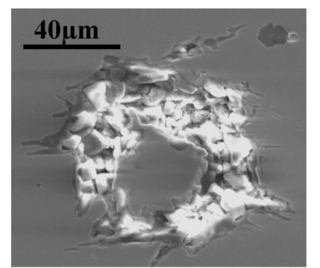

S8 of $3000 \mathrm{~kg} / \mathrm{m}^{3}$ and $7800 \mathrm{~kg} / \mathrm{m}^{3}$ respectively. If all of these inclusions were $\mathrm{Al}_{2} \mathrm{O}_{3}$, they would correspond to $6.27 \mathrm{ppm}$ mass fraction and $3 \mathrm{ppm}$ total oxygen in the steel. The total number of inclusions in the ingot is much larger than this, however, considering that most of the inclusions are smaller than $20 \mu \mathrm{m}$. and sulfide inclusions are not counted. Note in Figs. 7 and 8 that the number of inclusions increases consistently with decreasing size, except for the few largest inclusions, which have random sizes, likely due to the small sample size. Assuming the same $\sim 85 \%$ fraction of inclusions smaller than $20 \mu \mathrm{m}$ as was measured in continuous cast steel $(30 \mathrm{ppm}),{ }^{33)}$ the ingot likely contains more than $40 \mathrm{ppm}$ total inclusions, or $19 \mathrm{ppm}$ total oxygen.

\subsection{Inclusion Types (Composition)}

\subsubsection{Pure Alumina Clusters}

Typical clusters of pure alumina inclusions are shown as $\mathrm{S} 1$ and S2 in Table 3 and in Fig. 9. Of the 78 total non-sulfide inclusions observed in the ingot, the majority (46) were pure alumina, which were almost all larger than $50 \mu \mathrm{m}$. Roughly half (25) of these were alumina clusters, while the others were irregular-shaped lumps of alumina. The clusters range from being partially surrounded by steel, as shown in S7 and S10, to being relatively exposed, as shown

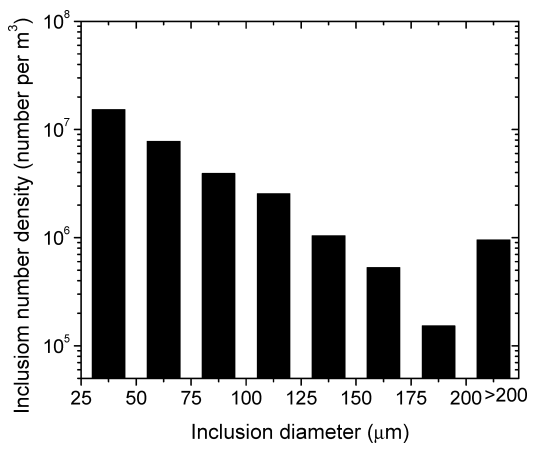

Fig. 8. Three-dimensional inclusion size distribution.

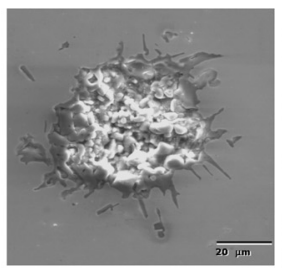

S9

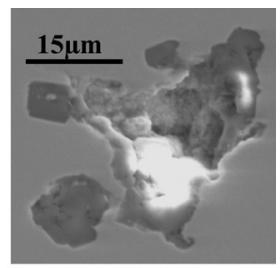

$\mathrm{S} 10$

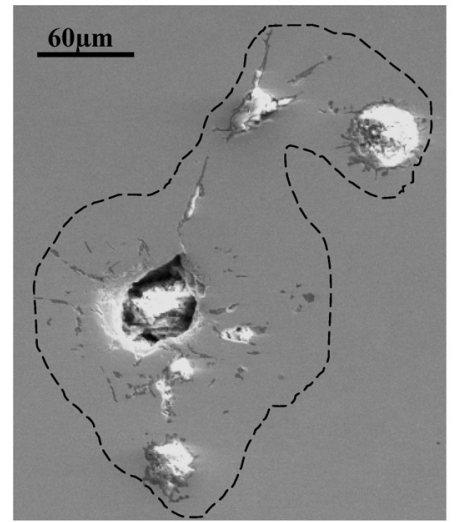

S11

Fig. 9. Morphology of pure alumina clusters. 


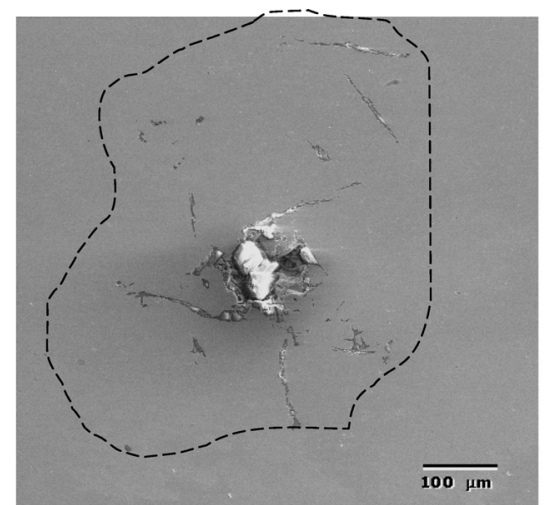

S12

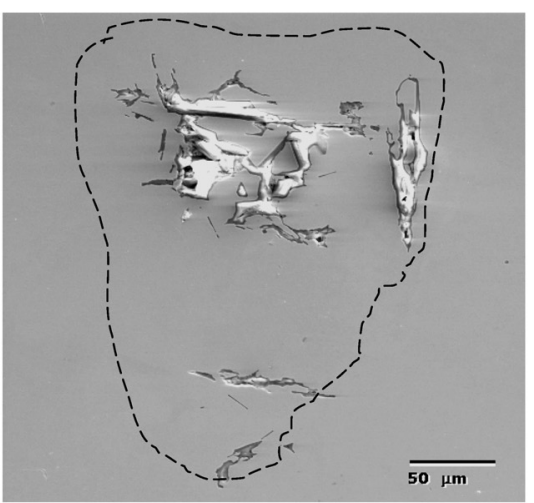

S13

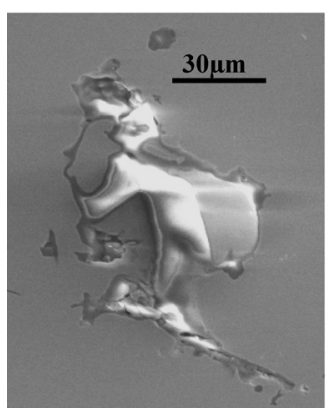

$\mathrm{S} 14$

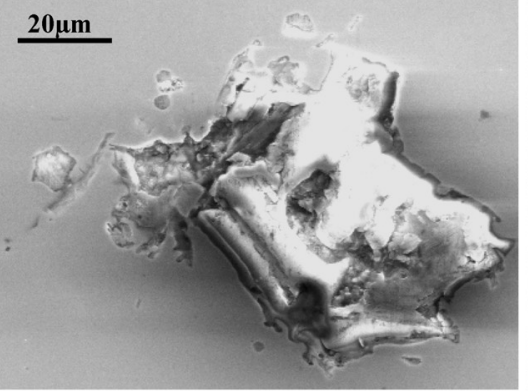

S15

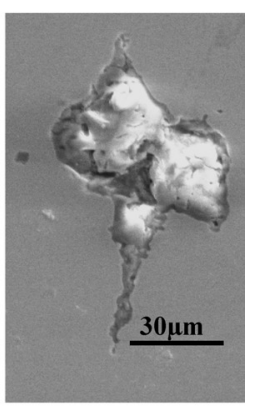

S16

Fig. 10. Morphology of lump pure alumina inclusions.

in S9. Some clusters even had steel trapped inside them, such as S8. Some alumina clusters were caught together in the liquid steel, as shown in S11. The center of S11 was dislodged during polishing and became dirty inside. The individual particles in the alumina clusters range from $1-5 \mu \mathrm{m}$ in diameter.

Possible sources of alumina clusters include deoxidation products, reoxidation by air absorption, Ostwald-Ripening of dendritic alumina, and sintering together (by collision) of many small alumina inclusions. Their composition was measured to be almost pure alumina, so they could not arise from refractory brick or slag. The clustering of deoxidation products is a possible source, but the strong refining practice should have prevented such large quantities with such high purity. The most likely source, at least of the large clusters, is air reoxidation. No perfect dendritic alumina inclusions were observed, which suggests that significant time has passed since original formation of the dendritic alumina in a high-oxygen environment. Air absorption likely took place between the ladle and the trumpet during teeming, or at the top surface of the molten steel in the ingot during filling. During the teeming process of this trial, there was no protection where the ladle drains into the trumpet, so air absorption is likely very severe at that location.

\subsubsection{Pure Alumina Lump Inclusions}

21 lump-shaped inclusions of pure alumina were observed on many samples, such as shown in Table 3 (S3) and Fig. 10. Some inclusions were sliced near their center, while others were sliced through an edge. Some inclusions lumps appear to be an aggregation of many thick needleshaped alumina inclusions that collided together, such as shown in S3, S12, and S13. Others are simply alumina lumps, such as S14, S15 and S16. The formation mechanism of these lump inclusions needs further investigation.

\subsubsection{Alumina Clusters with Exogenous Inclusions}

Several multi-component clusters that contained alumina and other exogenous inclusions were observed, as shown in Fig. 11. These inclusions likely have a multi-stage formation mechanism. Their complicated composition suggests that alumina particles combined with mold flux, broken lining refractory, and/or ladle slag. Micrograph S17 shows a $\sim 250 \mu \mathrm{m}$ irregular cavity with some inclusions remaining inside, which means that most of the inclusion was polished away. The composition at location 1 is $\mathrm{Al}_{2} \mathrm{O}_{3} 69.94 \%$, $\mathrm{MgO} 15.84 \%$, $\mathrm{FeO} 4.79 \%, \mathrm{~K}_{2} \mathrm{O} 7.32 \%, \mathrm{Na}_{2} \mathrm{O} \quad 0.76 \%$, $\mathrm{ZrO}_{2} 1.37 \%$, which suggests that this inclusion was from mold flux. The inclusion at location 2 is a pure alumina cluster, larger than $50 \mu \mathrm{m}$. When large exogenous inclusions move through the liquid steel, they may grow by nucleating other compounds from the supersaturated molten steel, or by simply colliding with other inclusions. Inclusions S18 and S19 are examples of a large alumina cluster capturing exogenous inclusions from the lining refractory $\left(\mathrm{Al}_{2} \mathrm{O}_{3} 84.41 \%, \mathrm{MgO} 5.77 \%, \mathrm{FeO} 2.96 \%, \mathrm{CaO}\right.$ $2.57 \%$ ). Inclusion $\mathrm{S} 19$ is comprised of $\mathrm{Al}_{2} \mathrm{O}_{3} 76.71 \%$, $\mathrm{MgO} 23.29 \%$, and is a compound inclusion cluster.

\subsection{4. $\mathrm{Al}_{2} \mathrm{O}_{3}-\mathrm{MgO}$ Inclusions}

Many (17) large inclusions of $\mathrm{Al}_{2} \mathrm{O}_{3}-\mathrm{MgO}$ were found, such as shown in S18, S19 in Fig. 11, and S20, S21 in Fig. 12. Their compositions are similar to ladle well block, and their shape is irregular with $20-30 \mu \mathrm{m}$ size. These inclusions may have formed by erosion of the ladle well block, or by alumina clusters firstly attaching to the surface of the well block as a clog, later becoming dislodged into the 


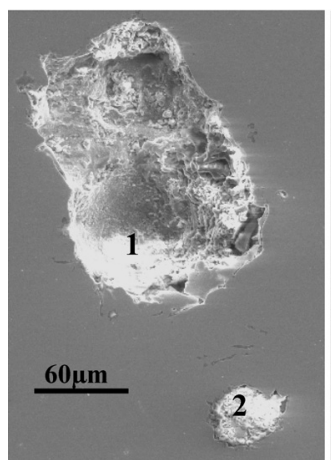

S17

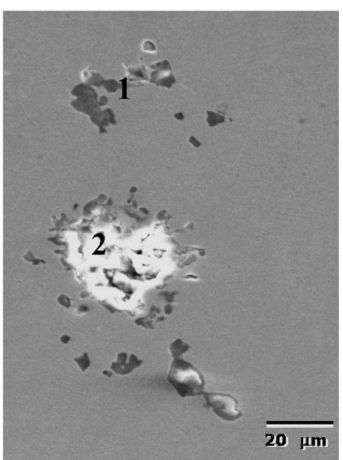

$\mathrm{S} 18$

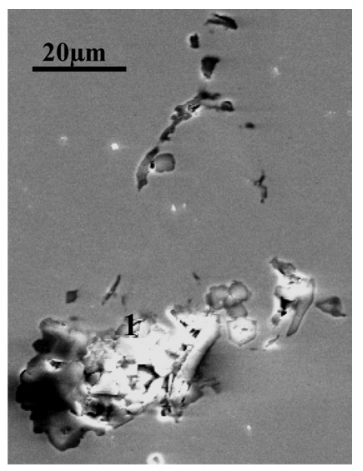

S19

Fig. 11. Alumina clusters with exogenous inclusions.

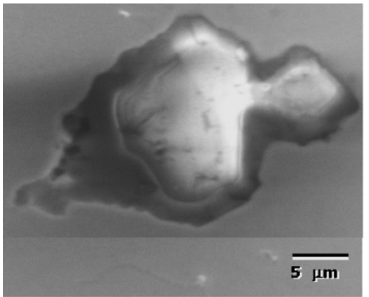

$\mathrm{S} 20\left(\mathrm{Al}_{2} \mathrm{O}_{3} 71.72, \mathrm{MgO} 23.56, \mathrm{FeO} 1.82, \mathrm{MnO} 2.90\right)$

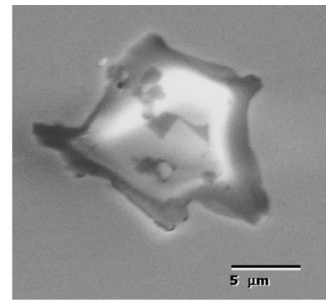

$\mathrm{S} 21\left(\mathrm{Al}_{2} \mathrm{O}_{3} 89.26, \mathrm{MgO} 10.74\right)$
Fig. 12. $\mathrm{Al}_{2} \mathrm{O}_{3}-\mathrm{MgO}$ inclusions.

liquid steel, perhaps reacting with well block material, and finally being captured by the solidified shell. The detailed formation mechanism of $\mathrm{Al}_{2} \mathrm{O}_{3}-\mathrm{MgO}$ inclusions needs to be further studied. The following mechanism was reported $^{34,35)}$ :

$$
\begin{aligned}
& (\mathrm{MgO})_{\text {in lining }}+\mathrm{C}_{\text {in steel or lining }} \rightarrow[\mathrm{Mg}]+\mathrm{CO} \uparrow \\
& 3[\mathrm{Mg}]+\left(\mathrm{Al}_{2} \mathrm{O}_{3}\right)_{\text {in lining or inclusion }} \rightarrow 2[\mathrm{Al}]+3(\mathrm{MgO})_{\text {in inclusion }}
\end{aligned}
$$

$$
\begin{aligned}
& \begin{array}{r}
4\left(\mathrm{Al}_{2} \mathrm{O}_{3}\right)_{\text {in inclusion or lining }}+3[\mathrm{Mg}] \\
\qquad=3\left(\mathrm{MgO} \cdot \mathrm{Al}_{2} \mathrm{O}_{3}\right)_{\text {in inclusion }}=2[\mathrm{Al}] \ldots \ldots \ldots . . .(4)
\end{array} \\
& \left(\mathrm{Al}_{2} \mathrm{O}_{3}\right)_{\text {in inclusion or lining }}+[\mathrm{Mg}]+[\mathrm{O}]=\left(\mathrm{MgO} \cdot \mathrm{Al}_{2} \mathrm{O}_{3}\right)_{\text {in inclusion }}
\end{aligned}
$$

$$
(\mathrm{MgO})_{\text {in lining }}+\left(\mathrm{Al}_{2} \mathrm{O}_{3}\right)_{\text {in inclusion }} \rightarrow\left(\mathrm{MgO} \cdot \mathrm{Al}_{2} \mathrm{O}_{3}\right)_{\text {in inclusion }}
$$

By these reactions, more $\mathrm{MgO}$ builds onto inclusions than $\mathrm{Al}_{2} \mathrm{O}_{3}$, thus $\mathrm{MgO}$ content of inclusions is higher than that of original ladle well block.

\subsubsection{Exogenous Inclusions from Ladle Inner Nozzle}

Seven inclusions were found to contain $\mathrm{Al}_{2} \mathrm{O}_{3}$ 94-98\%, $\mathrm{ZrO}_{2} 2-6 \%$, which is very similar to the composition of the ladle inner nozzle. The ladle inner nozzle $\left(\mathrm{Al}_{2} \mathrm{O}_{3} 94.00 \%\right.$, $\mathrm{ZrO}_{2} 2.50, \mathrm{SiO}_{2} 1.00 \%$, others $2.50 \%$ ) is the only lining refractory that contains zirconium oxide. Thus, during the teeming process, it appears that the ladle inner nozzle was eroded and dislodged inclusions into the liquid steel, likely due to excessive fluid velocity, high temperature and/or long time. These inclusions are shown in Fig. 13. Inclusions
S24 and S25 have been partially pulled out during polishing process.

\subsubsection{Inclusions from Mold Flux}

Six inclusions were observed that contained high $\mathrm{K}_{2} \mathrm{O}$ or $\mathrm{Na}_{2} \mathrm{O}$ composition. These inclusions are likely from entrapped mold flux, (S26), or perhaps from broken runner brick, (S27), as shown in Fig. 14. Some of these inclusions are very large, exceeding 150-600 $\mu \mathrm{m}$.

\subsubsection{Silica Based Inclusions}

Two spherical silica-based inclusions larger than $20 \mu \mathrm{m}$ were observed. An example is shown in Fig. 15, with composition $\mathrm{Al}_{2} \mathrm{O}_{3} 61.23 \%, \mathrm{SiO}_{2} 2.83 \%, \mathrm{CaO} 35.94 \%$. These inclusions may have originated from ladle slag. They are not mold flux because there is no $\mathrm{K}_{2} \mathrm{O}$ and $\mathrm{Na}_{2} \mathrm{O}$.

\subsubsection{Bubble-shaped Inclusions}

Several different kinds of bubble-shaped defects were observed in the steel samples, such as shown in Table 1 (S6) and in Table 4. These defects contain a ring of inclusions around the former boundary of the bubble, or in its wake. Their composition varies widely, but always include inclusions of pure sulfides $(\mathrm{MnS})$ and usually also compound $\mathrm{Al}_{2} \mathrm{O}_{3}-\mathrm{MgO}$ inclusions. Although the individual inclusions are small, the entire defect is dangerously large, with diameter of 50-300 $\mu \mathrm{m}$. These defects are believed to arise through the following mechanism:

Step 1: A moving bubble collides with inclusions which attach to most of its surface;

Step 2: Inclusions form a shell around most of the bubble surface;

Step 3: The gas bubble escapes (argon or CO) or reacts/ absorbs in the steel (air bubbles);

Step 4: The shell of inclusions is filled in with molten steel;

Step 5: Sulfides precipitate during solidification.

\subsubsection{Cavity and Holes}

Many different types of cavities and holes were found in the samples. Some of these simply arose during polishing by dislodging inclusions, such as shown in Table 1 (S1, S4), Fig. 9 (S11), Fig. 11 (S17), Fig. 13 (S24 and S25). Spherical bubble-shaped holes were likely created during solidification by the escape of gas bubbles $\left(\mathrm{N}_{2}\right.$ bubble, $\mathrm{CO}$ bubble, and possible argon bubble), such as shown in S29 and S30 


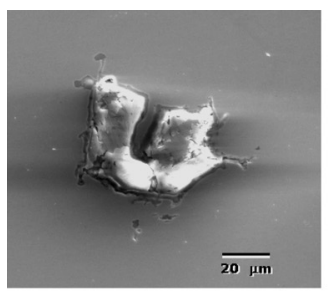

S22

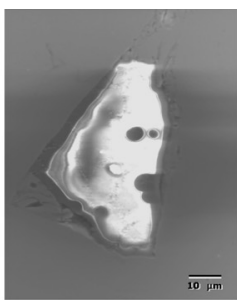

S23

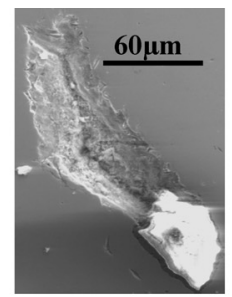

$\mathrm{S} 24$

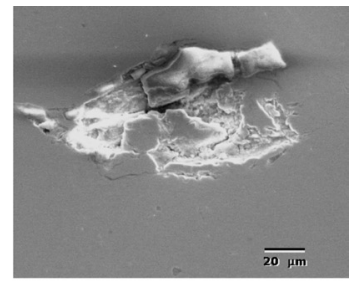

S25

Fig. 13. Exogenous inclusions from ladle inner nozzle.
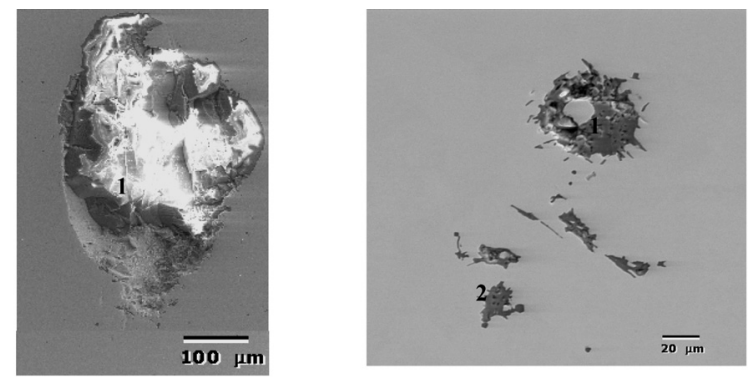

$\mathrm{Al}_{2} \mathrm{O}_{3} 22.05 \%, \mathrm{SiO}_{2} 47.02 \%, \mathrm{MgO} 1.88 \%, \mathrm{CaO} \quad 1: \mathrm{Al}_{2} \mathrm{O}_{3} 83.22, \mathrm{MgO} 4.36, \mathrm{~K}_{2} \mathrm{O} 10.26 \mathrm{CaO} 2.16$

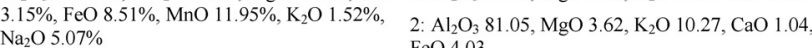
S26 $\mathrm{FeO} 4.03$

S27

Fig. 14. Inclusions from mold flux and runner brick.

in Table 4. Irregular-shaped holes were created during the final stages of solidification comprise interdendritic cavities called "micro-porosity". Examples are shown in S5 in Table 1, S36-42 in Table 5, and in Fig. 16.

The cavities from micro-porosity form due to liquid feeding problems into the interdendritic spaces, so were more often observed near the ingot center where the mushy zone is larger and liquid feeding is more difficult. They are often associated with sulfides, which concentrate in the same region due to microsegregation of S and Mn. Figure 16 shows several interesting examples. Sulfides are present along the dendrite boundaries (holes) in S37 and S38. The void cluster in S39 illustrates mild microporosity. Closeups of severe microporosity near the ingot centerline, shown in S40 and S42, show the jagged nature of the interior of voids. The void edges are the surfaces of dendrites, as revealed in S41, complete with classic secondary arms. A closeup of the dendrite surface in S43 shows MnS inclusions on the dendrite edges, which are likely the precipitated remnants of an interdendritic liquid film.

\subsubsection{Sulfide Inclusions}

A great number of pure sulfide $(\mathrm{MnS})$ inclusions were found in the steel samples. A few examples, are shown in S6 in Table 1, S29,30,31,32,35 in Table 4, S37, 38 and 43 in Fig. 16, and in Fig. 17. These inclusions often appear in clusters with a large size (exceeding $>100 \mu \mathrm{m}$ ) and are generally much greater than the individual inclusions. Sulfides tend to concentrate around the boundaries of former bubbles and near interdendritic cavities (S6 in Table 1, S29, 30, 31, 32, 35 in Table 4, S37, 38, 43 in Table 5).

\subsection{Summary of Ingot Inclusion Sources}

The compositions of all 78 of the observed non-sulfide inclusions are plotted on the ternary phase diagram in Fig.

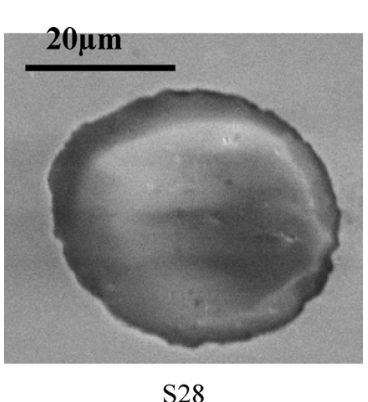

Fig. 15. Silica based inclusions.

Table 4. Bubble-shaped inclusion defects.

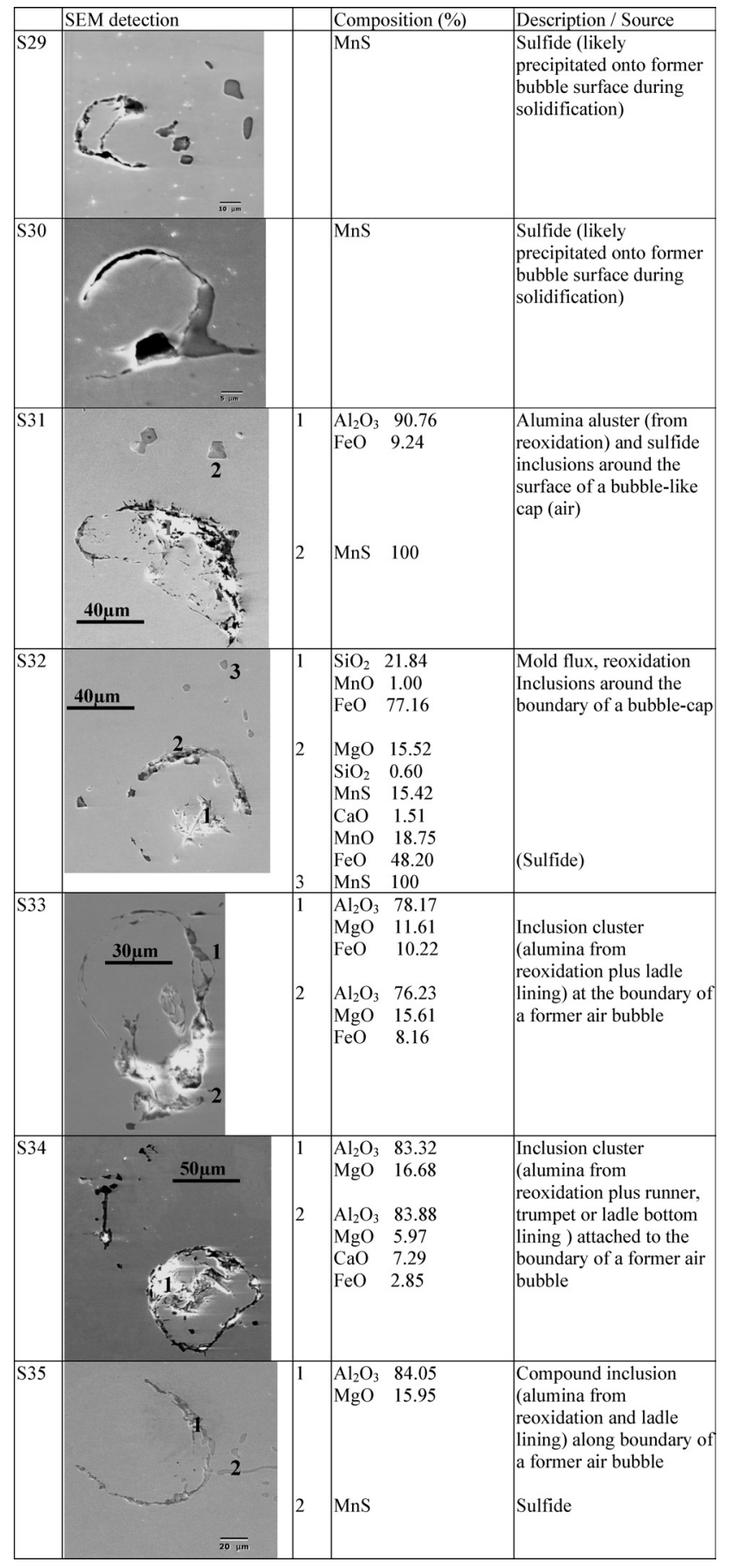

18. In total, $59 \%$ of the large inclusions $(>20 \mu \mathrm{m})$ were pure alumina or alumina/FeO inclusions. These inclusions 
are believed to arise mainly from air reoxidation. The most likely places for air absorption are the connection between ladle and trumpet during teeming, and the top surface of the molten steel in the ingot during filling. Of the remaining inclusions having complex composition, $22 \%$ were from ladle well block refractory, $9 \%$ from the ladle inner nozzle,

Table 5. Sources of $>20 \mu \mathrm{m}$ inclusions in ingot.

\begin{tabular}{|l|c|c|}
\hline & Number & Percentage (\%) \\
\hline Alumina (air reoxidation) & 46 & $59 \%$ \\
\hline ladle well block & 17 & $22 \%$ \\
\hline Ladle inner nozzle & 7 & $9 \%$ \\
\hline Mold flux & 6 & $8 \%$ \\
\hline slag inclusions (not mold flux) & 2 & $2 \%$ \\
\hline trumpet and runner bricks & 0 & $0 \%$ \\
\hline
\end{tabular}

$8 \%$ from mold flux, and $2 \%$ from slag inclusions (not mold flux), as shown in Table 5. Mold flux inclusions are more important than indicated here, because the two huge inclusions detected by ultra-sonic detection are not included. In addition, a much larger number of pure sulfide inclusions and smaller inclusions of all types were also observed.

\section{Summary and Conclusions}

(1) A comprehensive investigation of inclusions in industrial bottom-teemed ingots of plain carbon steel was undertaken using ultrasonic detection, optical microscope observation, and SEM analysis. The composition, size distrib-

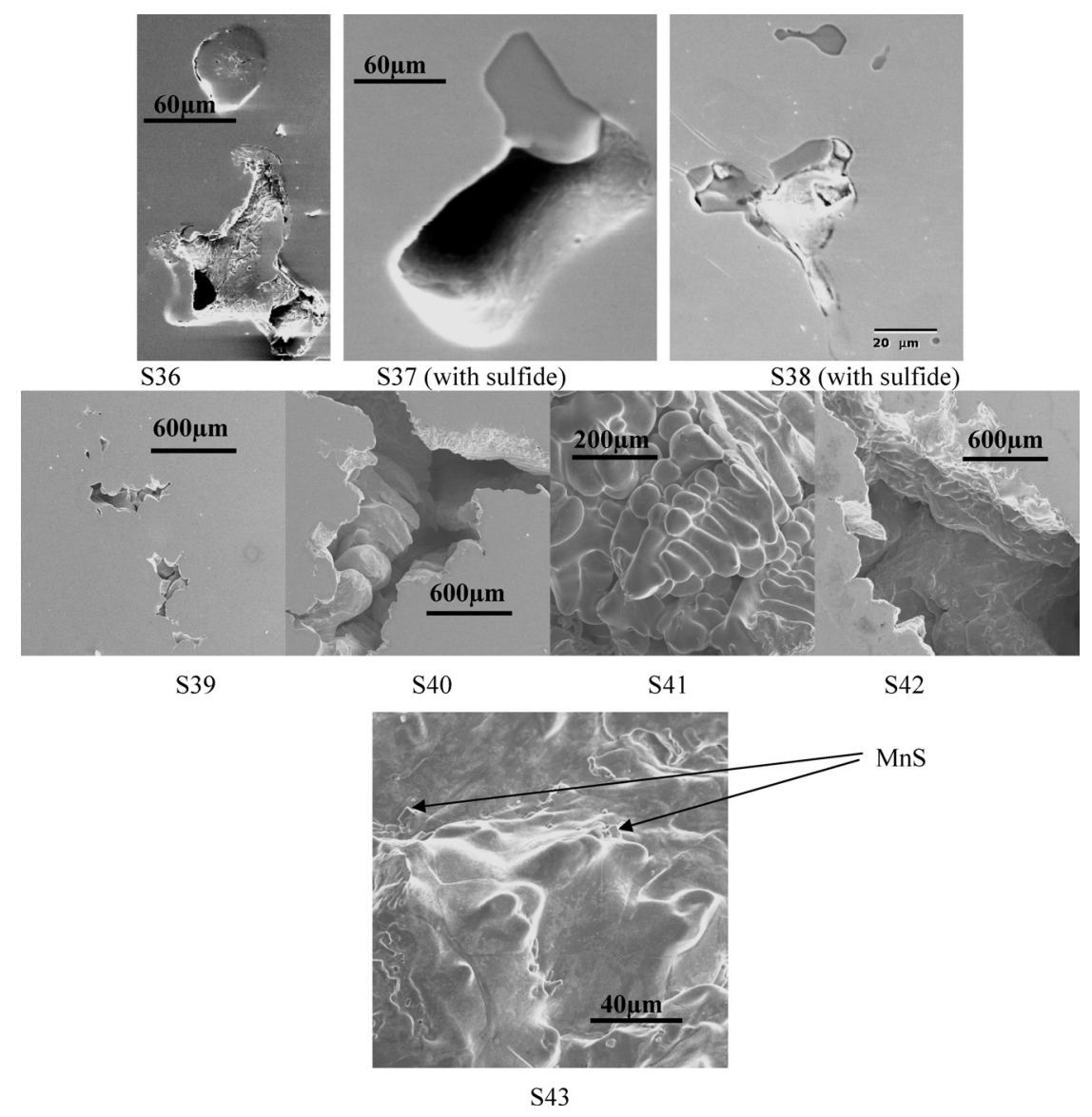

Fig. 16. Cavity and holes found on the steel samples.

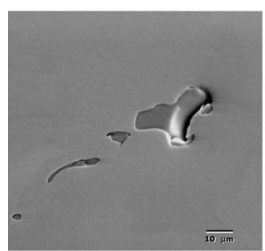

S44

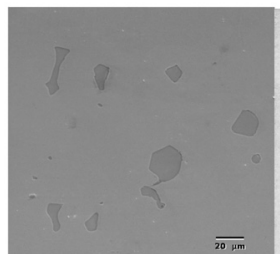

S48

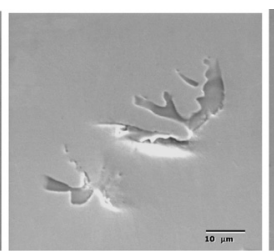

S45

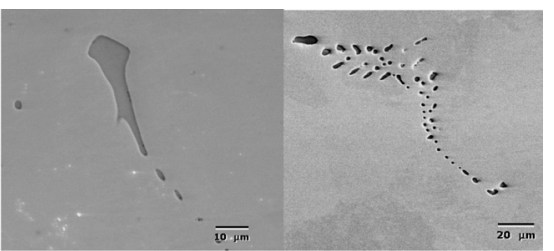

S46

S47

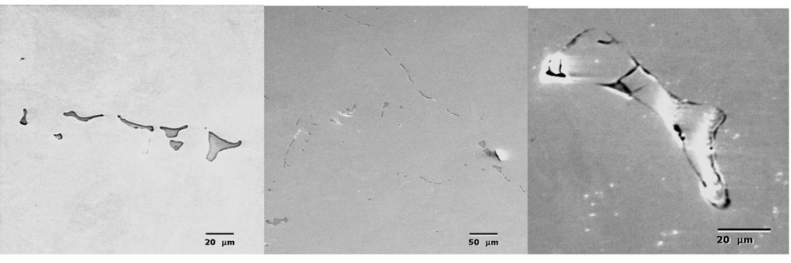

S50

S51

Fig. 17. Sulfide inclusions. 


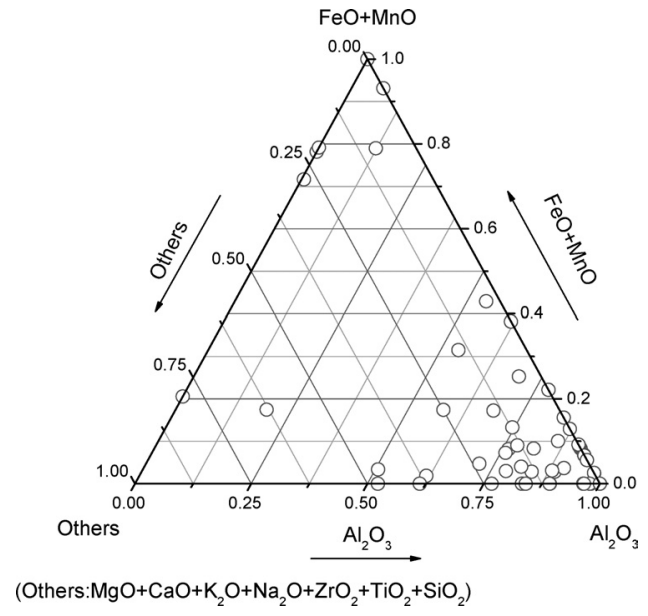

Fig. 18. Composition of non-sulfide inclusions observed in the samples.

ution, entrapment locations, and sources of ingot inclusions were revealed from the inclusions larger than $20 \mu \mathrm{m}$ that were observed.

(2) The largest inclusions exceeded $20 \mathrm{~mm}$ and originated from mold flux in the ingot.

(3) Extrapolation from the $35000 \mathrm{~mm}^{2}$ of samples observed to the total volume suggests total $3.23 \times 10^{7}$ inclusions larger than $20 \mu \mathrm{m}$ per $\mathrm{m}^{3}$ steel in the ingot, with a size distribution increasing in number with decreasing size.

(4) At every height, inclusions are randomly distributed around the ingot perimeter, but there is slight trend of more inclusions towards the trumpet side of the ingot near the ingot bottom.

(5) The largest inclusion source appears to be reoxidation, as evidenced by $59 \%$ of the ingot inclusions composed of pure alumina clusters and lumps.

(6) Eroded refractories from the ladle well block and ladle inner nozzle bricks accounted for $31 \%$ of the ingot inclusions.

(7) Evaluation of ingot macro-inclusions requires a combination of detection methods, including ultrasonic detection to find the large rare inclusions, optical microscope observation to find the inclusions $>20$ microns, and SEM evaluation to confirm the composition and origin of previously-detected inclusions.

\section{Acknowledgements}

This work was supported by a grant from the Ingot Metallurgy Forum, which is gratefully acknowledged. Thanks are also extended to Elwood Quality Castings for conducting the industrial trials, and to Danielle Q. Baird at Timken, Inc. for help with planning. Microscopy was performed using the facilities at the Center for Microanalysis of Materials at the University of Illinois, which is partially supported by the U.S. Department of Energy under grant DEFG02-91-ER45439. Finally, thanks are owed to Jim Mabon and to the Machine Shop at the Department of Mechanical \& Industrial Engineering for help with sample preparation.

\section{REFERENCES}

1) Steel Statistical Yearbook 2002, ed. by International Iron and Steel Institute, Brussels, (2002), 13.

2) E. Fuchs and P. Jonsson: High Temp. Mater. Process., 19 (2000), 333.

3) K. Sumitomo, M. Hashio, T. Kishida and A. Kawami: Iron Steel Eng., 62, (1985), No. 3, 54.

4) P. K. Trojan: ASM Handbook, 15 (Casting), ASM International, Ohio, (1988), 88.

5) G. Pomey and B. Trentini: Int. Conf. on Production and Application of Clean Steels, The Iron and Steel Institute, London, (1970), 1.

6) A. G. Franklin: Int. Conf. on Production and Application of Clean Steels, The Iron and Steel Institute, London, (1970), 241.

7) Y. Miki, H. Kitaoka, T. Sakuraya and T. Fujii: Tetsu-to-Hagané, 78 (1992), 431.

8) D. C. Hilty and D. A. R. Kay: 43rd Electric Furnace Steelmaking Conf. Proc., ISS, Warrendale, PA, USA, (1985), 237.

9) F. B. Pickering: Int. Conf. on Production and Application of Clean Steels, The Iron and Steel Institute, London, (1970), 75.

10) S. E. Lunner: Int. Conf. on Production and Application of Clean Steels, The Iron and Steel Institute, London, (1970), 124.

11) J. D. Thomas, R. O. Russell and T. R. Garcia: 69th Steelmaking Conf. Proc., ISS, Warrendale, PA, (1986), 300.

12) J. C. C. Leach: Int. Conf. on Production and Application of Clean Steels, The Iron and Steel Institute, London, (1970), 105.

13) M. M. McDonald and D. C. Ludwigson: J. Test. Eval., 11 (1983), 165.

14) Special Report No. 63,: Surface Defects in Ingots and their products, Ingot Surface Defects Sub-Committee (Steelmaking Division) of the British Iron and Steel Research Association, (1958), 42.

15) P. W. Wright: Met. Forum, 2 (1979), 82.

16) S. Riaz, K. C. Mills and K. Bain: Ironmaking Steelmaking, 29 (2002), 107.

17) G. B. Hassall, K. G. Jones and N. Warman, M: Ironmaking Steelmaking, 29 (2002), 383.

18) R. L. Shultz: 62nd Steelmaking Conf. Proc., ISS, Warrendale, PA, (1979), 232.

19) R. Schlatter: Steel Times, (1986), 432

20) A. Staronka and W. Golas: Arch. Eisenhüttenwes., 51 (1980), 403.

21) P. Kazakevitch and M. Olette: Int. Conf. on Production and Application of Clean Steels, The Iron and Steel Institute, London, (1970), 42

22) A. W. Cramb and I. Jimbo: Iron Steelmaker (ISS Trans.), 11 (1990), 67.

23) K. Suzuki, K. Taniguchi and T. Takenouchi: Tetsu-to-Hagané, 61 (1975), S96.

24) M. Iguchi, Y. Sumida, R. Okata and Z. Morita: Tetsu-to-Hagané, 79 (1993), 33

25) H. F. Marston: 69th Steelmaking Conf. Proc., ISS, Warrendale, PA, (1986), 107.

26) J. G. Bartholomew, R. L. Harvey and D. J. Hurtuk: 69th Steelmaking Conf. Proc., ISS, Warrendale, PA, (1986), 121.

27) A. P. Ogurtsov: Steel USSR, 18 (1988), 225.

28) Z. Chen, J. Liu and J. Zeng: Iron Steel (China), 18 (1983), 43.

29) M. D. Maheshwari and T. Mukherjee: Tisco, 26 (1979), 9.

30) K. P. Hughes, C. T. Schade and M. A. Shepherd: Iron Steelmaker, 22 (1995), 35.

31) L. Zhang and B. G. Thomas: ISIJ Int., 43 (2003), 271.

32) J. Cheng, R. Eriksson and P. Jonsson: Ironmaking Steelmaking, 30 (2003), 66.

33) L. Zhang, B. G. Thomas, K. Cai, L. Zhu and J. Cui: Proc. ISS Tech2003, ISS, Warrandale, PA, (2003), 141.

34) V. Brabie: ISIJ Int., 36 (1996), S109.

35) K. Fujii, T. Nagasaka and M. Hino: ISIJ Int., 40 (2000), 1059. 